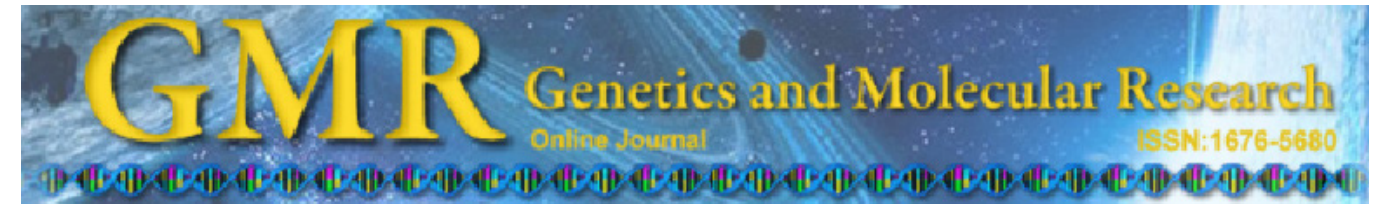

Methodology

\title{
An alternate method for DNA and RNA extraction from clotted blood
}

\section{Z. Zakaria, S.H. Umi, S.S. Mokhtar, U. Mokhtar, M.Z. Zaiharina,} A.T.A. Aziz and B.P. Hoh

Genomics Laboratory, Institute of Medical Molecular Biotechnology, Faculty of Medicine, Universiti Teknologi MARA, Sungai Buloh, Selangor, Malaysia

Corresponding author: B.P. Hoh

E-mail: hbpeng@salam.uitm.edu.my

Genet. Mol. Res. 12 (1): 302-311 (2013)

Received May 17, 2012

Accepted November 3, 2012

Published February 4, 2013

DOI http://dx.doi.org/10.4238/2013.February.4.4

ABSTRACT. We developed an alternative method to extract DNA and RNA from clotted blood for genomic and molecular investigations. A combination of the TRIzol method and the QIAamp spin column were used to extract RNA from frozen clotted blood. Clotted blood was sonicated and then the QIAamp DNA Blood Mini Kit was used for DNA extraction. Extracted DNA and RNA were adequate for gene expression analysis and copy number variation (CNV) genotyping, respectively. The purity of the extracted RNA and DNA was in the range of 1.8-2.0, determined by absorbance ratios of $\mathrm{A}_{260}: \mathrm{A}_{280}$. Good DNA and RNA integrity were confirmed using gel electrophoresis and automated electrophoresis. The extracted DNA was suitable for qPCR and microarrays for CNV genotyping, while the extracted RNA was adequate for gene analysis using RT-qPCR.

Key words: Clotted blood; DNA extraction; RNA extraction; Sonication 


\section{INTRODUCTION}

Medical genomic research has risen dramatically recently with the availability of various high-throughput technological advancements such as microarray and next-generation sequencing. However, obtaining DNA and RNA with good quality is challenging. Peripheral blood is one of the major sources for genomic DNA and RNA. New blood samples are usually obtained from consenting subjects for genomic studies, and providing these samples may be a nuisance to the subjects.

Methods have been developed to obtain DNA from human clotted blood, which is normally discarded (Kanai et al., 1994; Salazar et al., 1998; Basuni et al., 2000; Adkins et al., 2002; Se Fum Wong et al., 2007). These strategies could essentially minimize the volume of blood needed, especially when working with infants. Obtaining good-quality DNA from clotted blood for genomic studies is crucial for accurate analysis, as has been proven by Cukier et al. (2009).

The use of RNA for genetic studies has rapidly expanded in molecular research. Many advanced applications of gene expression in whole genomic studies require a certain amount of RNA for analysis. RNA is a much less stable molecule than DNA, and obtaining RNA with good quality and high yield from clotted blood is challenging. Precautions must be taken to avoid contamination with RNAses, proteins, and genomic DNA, especially during RNA preparation and storage, while also obtaining maximum yield. Good-quality RNA is important in modern molecular biological methods such as reverse transcriptase-quantitative polymerase chain reaction (RT-qPCR) and microarray analysis. In this study, we developed alternative method for extracting DNA and RNA from clotted blood and showed that both DNA and RNA is obtained with sufficient quality for use in copy number variation (CNV) genotyping and gene expression studies, respectively.

\section{MATERIAL AND METHODS}

\section{Clinical material}

Ethics approval was obtained for a study of the host genetics of dengue [Ministry of Health: NMRR-09-1128-4211; Universiti Teknologi MARA: 600-RMI (5/1/6), 600-RMI $(5 / 1 / 6)]$. Three milliliters of peripheral blood was collected from dengue patients at Sungai Buloh Hospital, Selangor, Malaysia, in plain tubes (BD, USA). Samples were spun, and the separated serum was used for serological tests. Clotted blood was kept at $-80^{\circ} \mathrm{C}$ until use.

\section{Genomic DNA extraction}

Before extraction, clotted blood samples were thawed and sonicated at $100 \mathrm{~Hz}$ and $4^{\circ} \mathrm{C}$ for $3 \mathrm{~h}$. Blood samples were then macerated with autoclaved disposable wooden applicator sticks. Approximately $200 \mu \mathrm{L}$ was transferred to a sterile $1.5-\mathrm{mL}$ microcentrifuge tube, and $400 \mu \mathrm{L} 1 \mathrm{X}$ red blood cell (RBC) lysis buffer was added. The tubes were inverted for $30 \mathrm{~s}$ and quick-spun to ensure that none of the samples were stuck to the tube caps. The mixtures were incubated overnight at $37^{\circ} \mathrm{C}$ and then washed with $\mathrm{RBC}$ lysis buffer until a white pellet formed. Genomic DNA was extracted from the pellet using a QIAamp DNA Blood Mini Kit 
(Qiagen, Germany) following manufacturer instructions. Briefly, $15 \mu \mathrm{L} 100 \mathrm{mg} / \mathrm{mL}$ proteinase $\mathrm{K}$ and $200 \mu \mathrm{L}$ buffer AL were added to the pellet, mixed thoroughly by inversion 10 times, and incubated at $56^{\circ} \mathrm{C}$ for $30 \mathrm{~min}$. After incubation, the tube was briefly centrifuged, and $200 \mu \mathrm{L}$ ethanol (96-100\%) was added to the reaction mixture. The reaction mixture was then transferred to the QIAamp spin column and centrifuged at $8000 \mathrm{rpm}$ for $1 \mathrm{~min}$. The QIAamp spin column was then placed in a clean $2-\mathrm{mL}$ tube and $500 \mu \mathrm{L}$ buffer AW1 was added. The spin column was centrifuged at $800 \mathrm{rpm}$ for $1 \mathrm{~min}$ and placed into a new collection tube. Five hundred-microliter buffer AW2 was added, and the column was centrifuged at 14,000 rpm for 3 min. The QIAamp spin column was then placed in a new $1.5-\mathrm{mL}$ microcentrifuge tube, 75 $\mu \mathrm{L}$ buffer AE (elution buffer) was added, and the tube was incubated at room temperature for $20 \mathrm{~min}$. Before the final centrifugation at $8000 \mathrm{rpm}$ for $3 \mathrm{~min}, 50 \mu \mathrm{L}$ double-distilled water was added into the spin column and incubated at room temperature for $15 \mathrm{~min}$. The eluted DNA was stored at $-20^{\circ} \mathrm{C}$ until further use.

\section{RNA extraction}

The TRIzol method was combined with a Qiagen QIAamp spin column for the isolation of RNA from clotted blood. A total of $1 \mathrm{~mL}$ clotted blood was incubated at $4{ }^{\circ} \mathrm{C}$ with 50 $\mathrm{mL} \mathrm{RBC} \mathrm{lysis} \mathrm{buffer} \mathrm{for} 30 \mathrm{~min}$ and spun down, and the supernatant was discarded. The step was repeated with $1 \mathrm{~mL} \mathrm{RBC}$ lysis buffer followed by $1 \mathrm{~mL}$ phosphate-buffered saline until the resulting pellet was cleared. Eight hundred-microliter TRIzol reagent was added to the pellet and vortexed immediately for $15 \mathrm{~s}$ before incubation at room temperature for $5 \mathrm{~min}$. Then, $200 \mu \mathrm{L}$ chloroform was added to the tube, and the solution was centrifuged for $14,000 \mathrm{rpm}$ for $15 \mathrm{~min}$ at $4^{\circ} \mathrm{C}$. Approximately $200 \mu \mathrm{L}$ aqueous phase was transferred to $700 \mu \mathrm{L}$ Qiagen RLT buffer in a clean tube, precipitated with $500 \mu \mathrm{L} 100 \%$ ethanol, and vortexed for $15 \mathrm{~s}$. The samples were applied to the QIAamp spin column, centrifuged, and washed twice with 500 $\mu \mathrm{L}$ buffer RPE and $750 \mu \mathrm{L} 80 \%$ ethanol. RNA was then eluted from the columns using $40 \mu \mathrm{L}$ RNAse-free water, quantitated with a NanoDrop ND-100 (Labtech International Ltd., UK), and stored at $-80^{\circ} \mathrm{C}$ until further use.

\section{Genomic DNA purity and integrity measurements}

The concentration and purity of genomic DNA were determined by measuring the 260- to 280-nm absorbance ratios $\left(\mathrm{A}_{260}: \mathrm{A}_{280}\right)$ using the NanoDrop ND-1000. Then, gel electrophoresis was used to determine the integrity of the DNA. Briefly, $3 \mu \mathrm{L}$ DNA was loaded onto $1 \%$ agarose gel with $5 \mu \mathrm{L}$ SYBR Safe (Invitrogen, USA) and electrophoresed for 30 min at $90 \mathrm{~V}$ followed by visualization under the gel imager (EasyDoc, Bio-Rad Laboratories, USA).

\section{RNA purity and integrity measurement}

RNA purity and concentration were determined by the absorbance ratios $\left(\mathrm{A}_{260}: \mathrm{A}_{280}\right)$ using the NanoDrop ND-1000 with ideal values of 1.8-2.0. Analysis by Experion (Bio-Rad Laboratories), an automated capillary-electrophoresis system, provided a framework for the standardization of RNA quality control. RNA integrity number (RIN) was calculated. 


\section{Microarray analysis using genotyping}

Genotyping was performed on DNA collected using the Genome-Wide Human single-nucleotide polymorphism (SNP) Nsp/Sty 6.0 assay (Affymetrix, USA), according to manufacturer instructions. Stringent filtering criteria were applied according to manufacturer recommendations, and the $\mathrm{CNV}$ of the sample was called using Genotyping Console (GTC 4.0, Affymetrix).

\section{qPCR genotyping}

CNV genotyping using qPCR was performed on the samples to countercheck the integrity of the DNA quality. The primers for genes FcGR3B F (5'-CAC CTT GAA TCT CAT CCC CAG GGT CTT G-3') and FcGR3B R (5'-CCA TCT CTG TCA CCT GCC AG$\left.3^{\prime}\right)$ were used as targets. Primers for genes FOXP2 F (5'-TGA CAT GCC AGC TTA TCT GTT T-3') and FOXP2 R (5'-GAG AAA AGC AAT TTT CAC ACA GTC C-3') were used as references. Amplification was carried out for $3 \mathrm{~min}$ at $95^{\circ} \mathrm{C}$, followed by 34 cycles of 20 $\mathrm{s}$ at $95^{\circ} \mathrm{C}, 61$ cycles of $20 \mathrm{~s}$ at $60^{\circ} \mathrm{C}, 15 \mathrm{~s}$ at $95^{\circ} \mathrm{C}$, and $30 \mathrm{~s}$ at $65^{\circ} \mathrm{C}$, using an IQ4 Bio-Rad Thermocycler (Bio-Rad Laboratories).

\section{RT-qPCR for gene expression}

Total RNA was reverse transcribed to complementary DNA using 5xi Script Reverse Transcriptase Supermix (Bio-Rad Laboratories). The primers for interleukin 6 (IL-6) were designed based on sequences published by Abe et al. (2005). Primer sequences were as follows: IL-6 forward primer (5'-CCA GTA CCC CCA GGA GAA GAT-3') and IL-6 reverse primer (5'-CGT TCT GAA GAG GTG AGT GGC-3') were used as targets, and glyceraldehyde 3-phosphate dehydrogenase (GAPDH) forward primer (5'-TGC ACC ACC AAC TGC TTA GC-3') and GAPDH reverse primer (5'-GGC ATG GAC TGT GGT CAT GAG-3') were used as references. PCR was conducted using an IQ4 Bio-Rad Thermocycler (Bio-Rad Laboratories) in a $25-\mu \mathrm{L}$ reaction mixture. Amplification was performed for 3 min at $95^{\circ} \mathrm{C}$ and $45 \mathrm{~s}$ at $60^{\circ} \mathrm{C}$, followed by 49 cycles of $30 \mathrm{~s}$ at $72^{\circ} \mathrm{C}, 1 \mathrm{~min}$ at $95^{\circ} \mathrm{C}$, and 1 $\min$ at $55^{\circ} \mathrm{C}$.

\section{RESULTS}

The quality of purified DNA from clotted blood was compared, and its integrity was evaluated with 3 assays. First, yields and purity of genomic DNA were determined through spectrophotometric analysis (Table 1). Second, the quality of DNA was observed using gel electrophoresis (Figure 1). Finally, microarray and qPCR analyses were performed to prove the good integrity and purity of the DNA (Figures 2 and 3 ). The purity (260/280) of the sample was expected to be within the range of 1.8-2.0, which is crucial for microarray and qPCR analysis. The success of the assay was an indicator of DNA quality. 


Table 1. Genomic DNA yield and purity.
\begin{tabular}{lcccc} 
\\
Sample ID & Concentration $(\mathrm{ng} / \mu \mathrm{L})$ & $\mathrm{A}_{260} / \mathrm{A}_{280}$ & Volume $(\mu \mathrm{L})$ & Amount $(\mathrm{ng})$ \\
\hline SB364 & 175.0 & 1.86 & 15 & 2625.0 \\
SB38 & 29.4 & 1.69 & 125 & 3675.0 \\
SB14 & 37.5 & 1.70 & 125 & 4687.5 \\
SB16 & 8.4 & 1.60 & 15 & 1050.0 \\
SB371 & 92.0 & 1.88 & 1380.0 \\
\hline
\end{tabular}

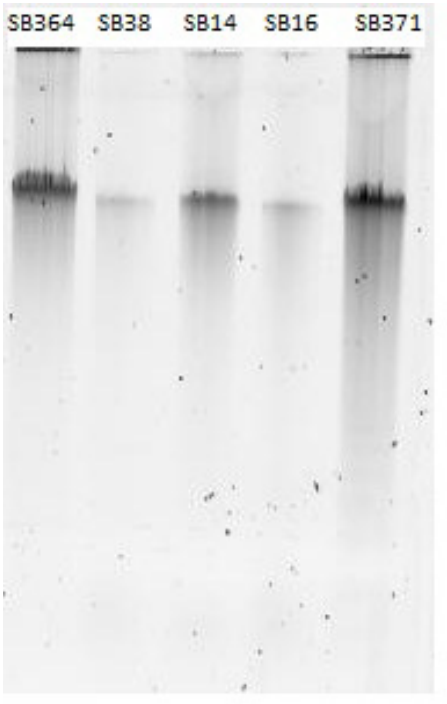

Figure 1. DNA banding patterns electrophoresed on $1 \%$ gel electrophoresis.
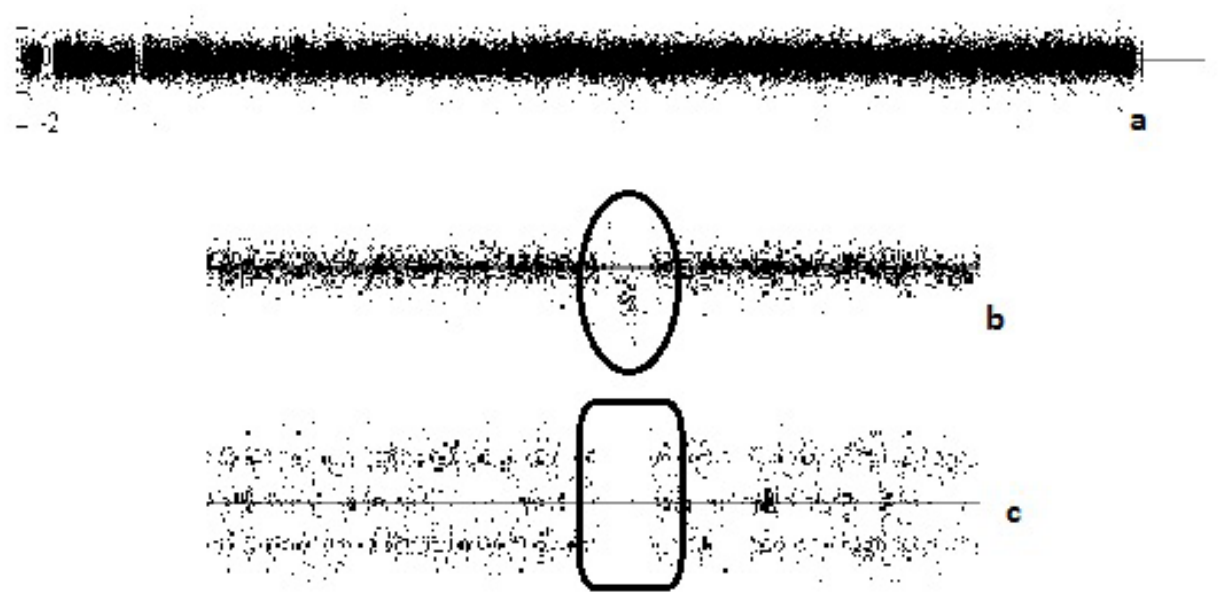

Figure 2. a. $\log _{2}$ ratio graph of a sample revealed from GTC 4.0 of Affymetrix indicates no copy number variation observed on chromosome 1 . b. $\log _{2}$ ratio graph on chromosome 3 observed with a copy number loss. c. B allele frequency graph showing a loss at the same position. 
a

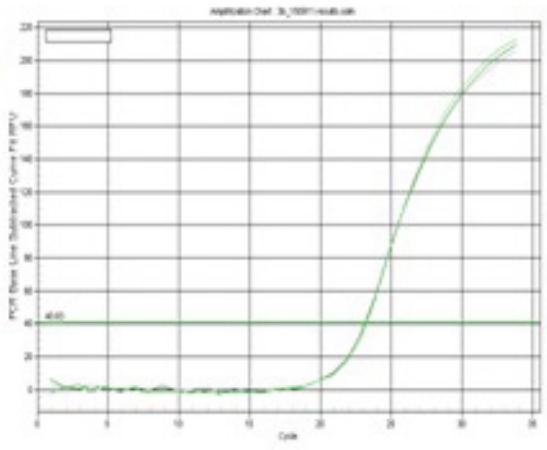

$c$

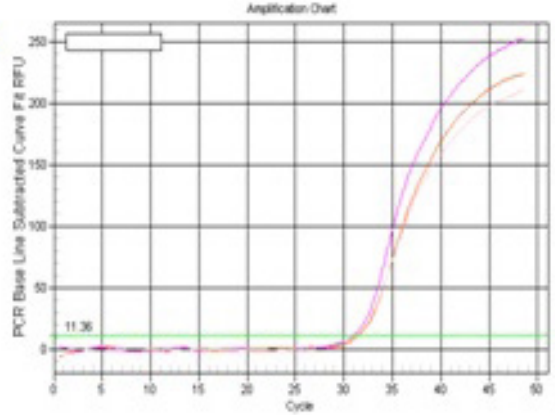

b

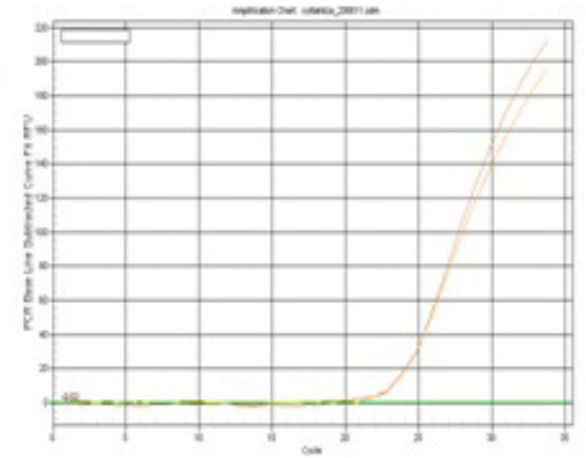

d

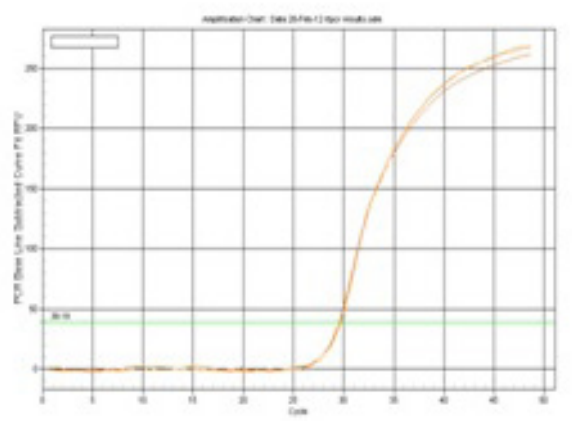

Figure 3. Triplicate amplification curves $\left(\mathrm{C}_{t}\right.$ curves $)$ of $q \mathrm{PCR}$ for DNA extracted from: a. whole blood and b. clotted blood. c. and d. are $\mathrm{C}_{\mathrm{t}}$ curves for the expression of the IL- 6 gene from clotted blood-extracted RNA.

Microarray analysis (Affymetrix SNP 6.0) showed that the genomic DNA used in this platform had a contrast quality control (QC) of more than 1.4 (Table 2). Contrast QC is a recommended QC metric for Genome-Wide SNP 6.0 assays, and the value of $\geq 0.4$ indicated that all steps of the assay were working as expected (GTC 4.0 user manual). QC call rate is another QC for this assay, and the manufacturer recommends $>86 \%$ as the cut-off value for good data (Nishida et al., 2008; Vogler et al., 2010). However, a Korean research group has used samples that have a genotyping rate of $>93 \%$ to eliminate false-positive results from lowquality genotyping data (Kang et al., 2008). Our research showed that the samples displayed good-quality genotyping with an average QC call rate of $93 \%$. The $\log _{2}$ ratio graph (see Figure 2 ) of the processed samples indicated a tentatively high-quality signal-to-noise ratio, proving the reliability of the DNA sample quality.

Table 2. Contrast quality control (QC) and QC call rate of genomic DNA run on Affymetrix SNP 6.0 assay.

\begin{tabular}{lcc}
\hline Sample ID & Contrast QC & QC call rate \\
\hline SB106 & 1.82 & 97.09 \\
SB27 & 2.47 & 97.29 \\
SB41 & 1.41 & 91.29 \\
SB263 & 1.00 & 90.77 \\
SB364 & 1.40 & 92.36 \\
\hline
\end{tabular}


For qPCR amplification, DNA quality was observed via triplicate amplification curves $\left(\mathrm{C}_{\mathrm{t}}\right.$ curves $)$, as shown in Figure $3 \mathrm{a}$ and $\mathrm{b}$. The amplification time for the triplicates of each samples occurred at approximately the same $\mathrm{C}_{\mathrm{t}}$ value indicating good-quality DNA.

Optical density measurements via NanoDrop and Experion (Bio-Rad Laboratories) were used in RNA quality assessment (Table 3; Figure 4). Both measurements showed similar readings, indicating the reliability of the assays. Additional measurement - namely, RIN - was calculated to assess RNA integrity by visualizing the $18 \mathrm{~S}$ and $28 \mathrm{~S}$ RNA bands. An RIN of $<5$ indicates total good-quality RNA, and $>8$ indicates perfect total RNA for genomic applications (Fleige and Pfaffl, 2006). We obtained an RIN of 7 from clotted blood samples. In addition, a decreased 28S:18S ratio or elevated threshold baseline indicates degradation of samples (Mueller et al., 2004). Gene expression profiles of the samples extracted were investigated using RT-qPCR, as shown in the $\mathrm{C}_{t}$ curves in Figure $3 \mathrm{c}$ and $\mathrm{d}$. Analysis of gene expression patterns in 4 samples (Figure 5) are presented as units of IL-6 as a target gene after normalization with GAPDH as the reference gene. The impact of RNA quality and purity also influenced the significance of differential gene expression. The data in Table 4 further show that the gene expression results we obtained appear to be influenced most by the purity of the individual samples themselves (see Table 3).

Table 3. Total RNA yield and purity.
\begin{tabular}{lccccc}
\hline Sample ID & \multicolumn{2}{c}{ Concentration $(\mathrm{ng} / \mu \mathrm{L})$} & & \\
\cline { 2 - 3 } & NanoDrop & Experion & $\mathrm{A}_{260} / \mathrm{A}_{280}$ & Volume $(\mu \mathrm{L})$ & Amount $(\mathrm{ng})$ \\
\hline SB72 & 18.75 & & & \\
SB166 & 18.24 & 11.14 & 1.61 & 50 & 937.5 \\
SB362 & 29.64 & 15.63 & 1.63 & 40 & 1185.6 \\
SB89 & 42.48 & 15.74 & 1.73 & 40 & 1699.2 \\
SB69 & 22.28 & 43.88 & 1.60 & 40 & 1114.0 \\
\hline
\end{tabular}

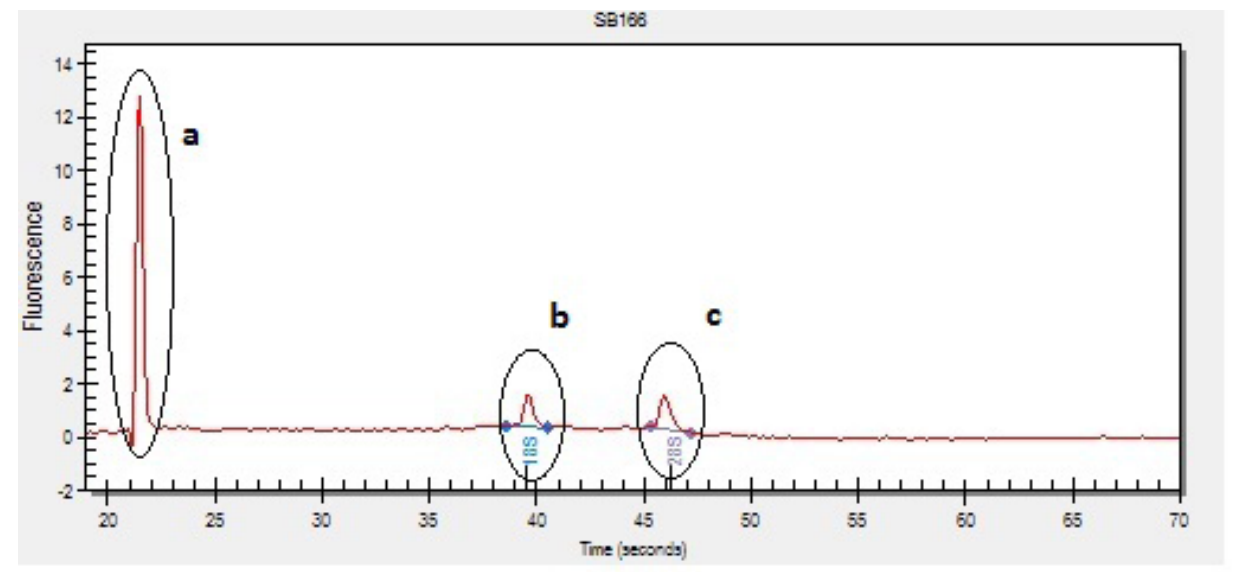

Figure 4. Chromatogram of micro-capillary electrophoresis [Experion (Bio-Rad, USA)] from RNA samples showing a small $28 / 18 \mathrm{~S}$ rRNA peak ratio with $\mathrm{RIN}=7.0$ was indicated by a shift in the electropherogram to shorter fragment sizes. a. marker. b. $18 \mathrm{~S}$. c. $28 \mathrm{~S}$. 


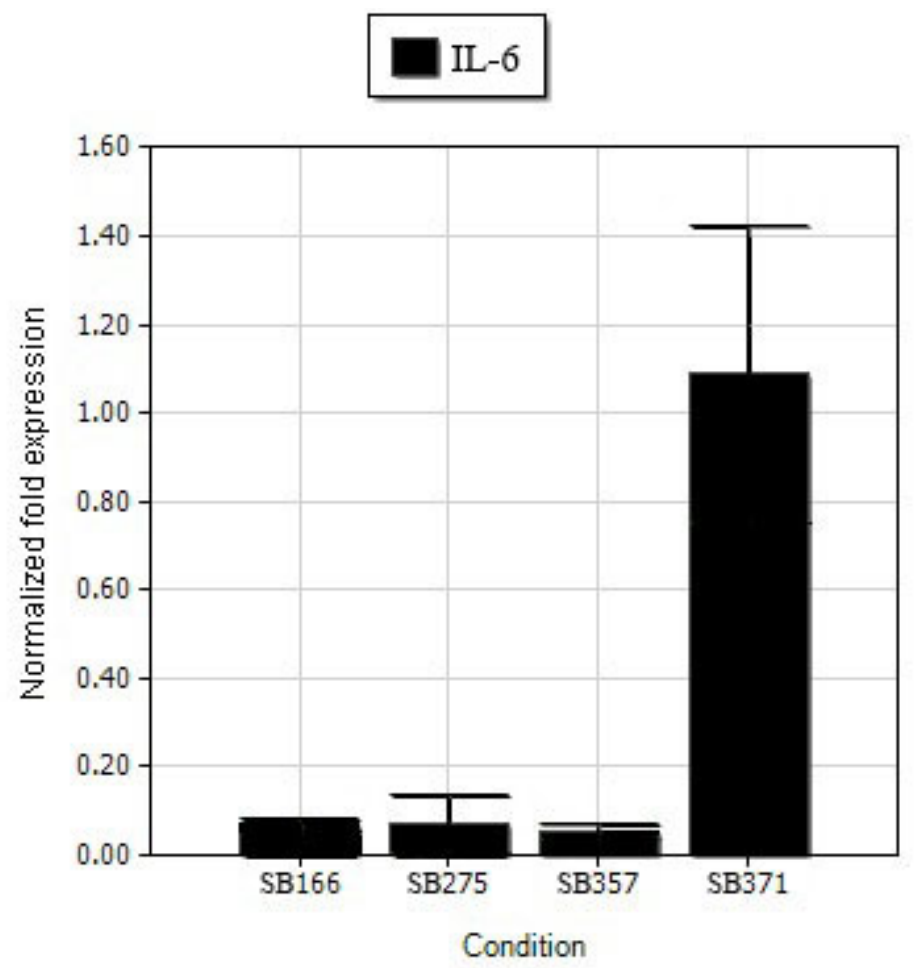

Figure 5. Higher expression of the IL-6 gene in the SB371 sample compared with others. Results are reported as relative units of IL- 6 as a target gene compared with GAPDH as the reference gene.

Table 4. IL-6 gene expression data of RNA extracted from clotted blood samples.

\begin{tabular}{lccccc}
\hline Sample ID & Expression & Expression SD & Corrected expression SD & Mean $C_{t}$ & $C_{t}$ SD \\
\hline SB166 & 0.06920 & 0.01587 & 0.01587 & 32.74 & 0.25020 \\
SB275 & 0.07292 & 0.06183 & 0.06183 & 35.70 & 1.21015 \\
SB357 & 0.05620 & 0.01674 & 0.01674 & 35.87 & 0.00000 \\
SB371 & 1.09037 & 0.33224 & 0.33224 & 28.89 & 0.07868 \\
\hline
\end{tabular}

$\mathrm{SD}=$ standard deviation.

\section{DISCUSSION}

The increasing volume of research that requires genomic DNA and RNA for either basic experimental procedures or high-throughput technology has led to a need to collect larger amounts of biomaterials - notably, peripheral blood - with excellent quality. Various types of blood collection tubes are often required to perform different biological investigations, including biochemical tests, serological tests, and also genomic studies. Volunteers or patients are inconvenienced when asked to provide high volumes of blood to meet the needs of researchers or diagnostic tests. Therefore, minimizing the blood volume taken from subjects is essential.

Several reports have suggested that DNA and RNA can be extracted from clotted 
blood with hazardous organic solvents such as phenol-chloroform (Basuni et al., 2000) and ethanol precipitation (Santella, 2006). Others have reported the use of a combination of $100 \%$ isopropanol and 70\% ethanol to extract DNA from clotted blood (Adkins et al., 2002). Clements et al. (2008) have compared 3 methods for DNA extraction - namely, a phenol-chloroform method, a silica gel membrane column method, and a modified salt precipitation method - and revealed that the silica column method retrieves DNA from both clotted blood and ethylenediaminetetraacetic acid-preserved blood with equally good results.

We developed an alternative method for extracting DNA from clotted blood; this method involved the use of sonication to enhance the rate of cell lysis, followed by manual grinding of clotted blood to maximize the volume of blood in liquid form. We believe that sonication breaks down the cell wall of clotted blood, easing the lysis process. Ultrasonication is a known method of mechanical cell disruption and is based on the high shear created by high-frequency ultrasound. Schoppee Bortz and Wamhoff (2011) used sonication for full-cellular disruption and maximum DNA recovery from fixed rat aortic smooth muscle cells. They suggested that sonication should be performed over a certain period. We performed sonication with hourly time intervals and found that $3 \mathrm{~h}$ was the most effective sonication time for clotted blood (data not shown) that would be later macerated. This mechanical cell disruption may also effectively break the walls of some fungi (Klimek-Ochab et al., 2011). Although we did not standardize the volume of the clotted blood samples during sonication, we made sure that they were nearly identical. Schoppee Bortz and Wamhoff (2011) have shown that cell density has no effect on outcome when using the same sonication treatment.

The lysed samples we obtained were sufficient for further DNA extraction using commercially available kits. The extracted DNA was genotyped using an SNP 6.0 Affymetrix platform with an average QC call rate of 93\% and contrast QC of 1.62. These values showed that the quality of the extracted DNA was sufficient for its use in microarray analysis. Similarly, the use of the extracted DNA for qPCR analysis was also successful.

On a separate note, conventional methods are nonspecific for single-stranded RNA and often exposed to interference from contaminants present in the sample (Imbeaud et al., 2005). De Paula et al. (2001) evaluated 3 well-established methods of RNA extraction from blood samples. The TRIzol and Chomczynski-Sacchi techniques showed an absence of amplification, and the authors believed it to be due to a loss of genetic material during the precipitation and washing procedures of these methods. The RNA yield obtained in this current study ranged from 730 to $5260 \mathrm{ng}$, with an average purity of 1.8. Although obtaining RNA of good quality from clotted blood is challenging, our alternative method proved its reliability, as evidenced by the RT-qPCR results. Gene expression profiles obtained from partially degraded RNA samples with still visible ribosomal bands exhibit a high degree of similarity (Schoor et al., 2003).

Therefore, our results are promising and proved that the sample integrity was reliable. Ultimately, our aim is to use collected biological materials fully while minimizing donor and patient discomfort. In summary, we successfully developed an alternative method to extract DNA and RNA from clotted blood for use in various genomic and molecular investigations.

\section{ACKNOWLEDGMENTS}

We thank Dr. Benedict Sim and Dr. Masliza Zaid for assistance in collecting blood samples from Sungai Buloh Hospital. Research supported in part by the Fundamental Re- 
search Grant Scheme (FRGS) [\#600 - RMI/ST/FRGS 5/3/Fst (69/2010)] and Dana Kecemerlangan research grants from Universiti Teknologi MARA [\#600 - RMI/STDANA 5/3/Dst $(281 / 2009)]$.

\section{REFERENCES}

Abe J, Jibiki T, Noma S, Nakajima T, et al. (2005). Gene expression profiling of the effect of high-dose intravenous Ig in patients with Kawasaki disease. J. Immunol. 174: 5837-5845.

Adkins KK, Strom DA, Jacobson TE, Seemann CR, et al. (2002). Utilizing genomic DNA purified from clotted blood samples for single nucleotide polymorphism genotyping. Arch. Pathol. Lab. Med. 126: 266-270.

Basuni AA, Butterworth LA, Cooksley G, Locarnini S, et al. (2000). An efficient extraction method from blood clots for studies requiring both host and viral DNA. J. Viral Hepat. 7: 241-243.

Clements DN, Wood S, Carter SD and Ollier WE (2008). Assessment of the quality and quantity of genomic DNA recovered from canine blood samples by three different extraction methods. Res. Vet. Sci. 85: 74-79.

Cukier HN, Pericak-Vance MA, Gilbert JR and Hedges DJ (2009). Sample degradation leads to false-positive copy number variation calls in multiplex real-time polymerase chain reaction assays. Anal. Biochem. 386: 288-290.

De Paula SO, Nunes C, Matos R, de Oliveira ZM, et al. (2001). Comparison of techniques for extracting viral RNA from isolation-negative serum for dengue diagnosis by the polymerase chain reaction. J. Virol Methods 98: 119-125.

Fleige S and Pfaffl MW (2006). RNA integrity and the effect on the real-time qRT-PCR performance. Mol. Aspects Med. 27: $126-139$

Imbeaud S, Graudens E, Boulanger V, Barlet X, et al. (2005). Towards standardization of RNA quality assessment using user-independent classifiers of microcapillary electrophoresis traces. Nucleic Acids Res. 33: e56.

Kanai N, Fujii T, Saito K and Tokoyama T (1994). Rapid and simple method for preparation of genomic DNA from easily obtainable clotted blood. J. Clin. Pathol. 47: 1043-1044.

Kang TW, Jeon YJ, Jang E, Kim HJ, et al. (2008). Copy number variations (CNVs) identified in Korean individuals. BMC Genomics 9: 492.

Klimek-Ochab M, Brzezińska-Rodak M, Żymańczyk-Duda E, Lejczak B, et al. (2011). Comparative study of fungal cell disruption - scope and limitations of the methods. Folia Microbiol. 56: 469-475.

Mueller O, Lightfoot S and Schroeder A (2004). RNA Integrity Number (RIN) - Standardization of RNA Quality Control. Agilent Application Note, Publication 5989-1165EN, 1-8.

Nishida N, Koike A, Tajima A, Ogasawara Y, et al. (2008). Evaluating the performance of Affymetrix SNP Array 6.0 platform with 400 Japanese individuals. BMC Genomics 9: 431.

Salazar LA, Hirata MH, Cavalli SA, Machado MO, et al. (1998). Optimized procedure for DNA isolation from fresh and cryopreserved clotted human blood useful in clinical molecular testing. Clin. Chem. 44: 1748-1450.

Santella RM (2006). Approaches to DNA/RNA extraction and whole genome application. Cancer Epidemiol. Biomarkers Prev. 15: 1585-1587.

Schoor O, Weinschenk T, Hennenlotter J, Corvin S, et al. (2003). Moderate degradation does not preclude microarray analysis of small amounts of RNA. Bio Techniques 35: 1192-1201.

Schoppee Bortz PD and Wamhoff BR (2011). Chromatin immunoprecipitation (ChIP): revisiting the efficacy of sample preparation, sonication, quantification of sheared DNA, and analysis via PCR. PLoS One 6: e26015.

Se Fum Wong S, Kuei JJ, Prasad N, Agonafer E, et al. (2007). A simple method for DNA isolation from clotted blood extricated rapidly from serum separator tubes. Clin. Chem. 53: 522-524.

Vogler C, Gschwind L, Röthlisberger B, Huber A, et al. (2010). Microarray-based maps of copy-number variant regions in European and Sub-Saharan populations. PLoS One 5: e15246. 